\title{
How COVID-19 Pandemic Affected the Treatment and Rehabilitation of Distal Radius Fracture? Data from a Peripheral General Hospital in Crete
}

\author{
Pantouvaki Anna ${ }^{* 1,3}$, Kastanis Grigorios ${ }^{2,3}$ \\ ${ }^{1}$ Department of Physiotherapy, General Hospital of Heraklion-Venizeleio, Crete, Greece \\ ${ }^{2}$ Department of Orthopaedic, General Hospital of Heraklion-Venizeleio, Crete, Greece \\ ${ }^{3}$ Reconstructive Hand Surgery unit, General Hospital of Heraklion-Venizeleio, Crete, Greece \\ *Corresponding author: Pantouvaki Anna; anna.pantouvaki@gmail.com
}

Received 12 August 2021;

Accepted 29 August 2021;

Published 04 September 2021

\begin{abstract}
Objectives: The purpose of this study is to evaluate the frequency of unstable distal radius fractures in adult population and the management performed in orthopaedic and physiotherapy department of the General Hospital" Venizeleio" in Heraklion-Crete re-organised due to pandemic period. In pandemic period, due to urgent needs of covid-19 patients, a lot of orthopaedic associations suggested some restrictions concerning the treatment of DRF. The aim of this study is to answer in two hypothetical questions. First, did patients with unstable DRF receive a conservative instead of surgical treatment and second is the protocol of rehabilitation program still the same or do the patients receive a modified rehabilitation program? Methods: Patients admitted in the emergency department of the hospital during pandemic period of 2020 with distal radius fracture surgically treated, were evaluated and data compared with those of pre-pandemic period. (2018-2019). $\underline{\text { Results: }}$ A number of 32, 35 and 42 patients with DRF were treated and hospitalized in 2018, 2019 (pre-pandemic period) and 2020 (pandemic period) respectively. The mean age of patients did not appear with any statistical difference. $(p=.93)$ between periods and causes of DRF did not change dramatically. Additionally, there was a remarkable variation in number of patients between the 1st and 2nd semesters of quarantine period. ( $\mathrm{p}=$.68). Conclusion: Adaptations in management of distal radius fracture during lockdown did not affect patient's surgical and rehabilitation treatment and functional outcomes. The mean age of patients treated, did not vary during pandemic period while the causes of DRF. But it was obligatory to adopt the rehabilitation treatment plan and the number of hospital visits due to Covid-19 precautions.
\end{abstract}

Keywords: Distal radius fracture, hand trauma, rehabilitation, Covid-19, rehabilitation

\section{Introduction}

Distal radius fracture (DRF) is the most common injury in emergency department with an incidence of $36.8 / 10$ persons per year in women and 9.0/10 persons per year in men over 35 years old rising in $9 \%$ by the age of 90years ${ }^{[1,2]}$. Huetteman et al. suggested that the average cost of care for a distal radius fracture patient was up to eight thousand dollars in the United States during 2009-2015 ${ }^{[1]}$. The distribution of these fractures depends on the age and the mechanism of injury. In geriatric patients, over 65 years old, with women having a higher risk than men of $15 \%$, DRF occur after a low energy trauma, usually a fall from standing height, due to frailty and osteoporotic factors ${ }^{[2]}$, On the other hand, in younger subjects the fracture is a result of high energy trauma due to a vehicle accident, fall from a height or work-related accidents and they usually suffer from comminute or displaced fractures which require definite surgical management. In stable distal radius fractures conservative treatment after closed reduction and immobilization in a plaster of Paris cast for 4-6 weeks to maintain an anatomical alignment is the elective treatment. In cases of unstable fractures following some criteria suggested by Lafontaine et al (age $>60$ years, dorsal angulations $>20^{\circ}$, dorsal comminution, fracture extension into the radiocarpal joint with intra-articular step-off more than $2 \mathrm{~mm}$ and associated ulnar fracture), surgical treatment is the elective procedure to restore radial bone articular surface and alignment in the wrist joint and prevent dysfunction. The most popular surgical technique is internal fixation with volar locking plate ${ }^{[2]}$.

The covid-19 pandemic has placed a remarkable pressure upon national health care services all over the world and had a significant effect on how health care services were delivered especially in urgent orthopaedic trauma ${ }^{[3,6]}$. In order to sustain orthopaedic and rehabilitation management and overcome this problem, it is described in literature that specific guidelines were 
suggested in treating various orthopaedic conditions admitted in emergency department according to epidemiological statistics of each country with British Orthopaedic association (BOA) to be one of the first published those. According to the recommendations of the BOA, DRF's could be managed conservatively at the very first period of acute pandemic situation with the thought that all complications could be thoroughly treated soon ${ }^{[4,5]}$.

Although many people readjusted their daily routines due to quarantine restrictions imposed by the countries, there is a quite significant number of trauma referrals, admissions, and operations during the pandemic period and especially in the second half of the pandemic situation in our hospital ${ }^{[6,8]}$.

The aim of this study was to answer in hypothetical two questions: Did patients with unstable DRF receive a conservative treatment instead of surgical and second is the protocol of rehabilitation program the same or to the patients receive restricted rehabilitation program?

\section{Materials and Methods}

This study was conducted in General hospital of Heraklion-Crete (Venizeleio) by the Reconstructive Hand Surgery unit in association with Orthopaedic and Physiotherapy departments after obtaining institutional ethics committee approval. Data were collected from the medical and rehabilitation records of the departments mentioned above, during pre-pandemic period (2018, 2019) and compared with data collected during pandemic period (2020). This study included all patients with distal radius fractures who were seeking medical attention in emergency department, who were surgically treated and hospitalized in the orthopaedic department and then followed a rehabilitation program when necessary, according to their personalized needs in the physiotherapy department of the hospital.

From 1st January of 2018 to 31 December 2019 all patients who surgically treated for distal radius fracture at the Orthopaedic department of General Hospital of Heraklion "Venizeleio" with a volar locking plate and met the criteria that have been introduced in this study defined the pre-pandemic period. From 1st January of 2020 to 31 December of 2020, all patients who treated for distal radius fracture at the same department and met the inclusion criteria, included also in the study.

Inclusion criteria of this research were, age $>20$ years old, surgical procedure with open reduction and fixation and only volar locking plate used and polytrauma. Exclusion criteria were age younger than 18 years-old, patients who received any surgical treatment from another hospital, corrective osteotomies, distal radius fracture with prior fixation with external fixation.

One hundred nine patients with DRF and an average age of 48,5 years old (range from 20 to 79) were stabilized by palmar locking plate due to unstable DRF. Most patients presented one or more comorbidities in their clinical history including diabetes mellitus, osteoporosis, hypertension, coronary artery disease, chronic obstructive pulmonary disease. From them, 42 cases reported during pandemic period and 32 and 35 during prepandemic period. The demographic data of the patients are shown in Table $\mathbf{I}$.

Despite the difficult pandemic situation all patients were assessed in Reconstructive Hand Surgery unit of the hospital in a follow up period of 2 weeks, 1, 3, 6 months while patients in prepandemic period were evaluated in 3-4 days post surgically, in 2 weeks, 1,3,6 and 12 months. Patients were given an appointment on a certain day and time for the postoperative follow-up following all hygiene precautions during the lockdown period.

Due to decrease of elective surgeries performed based on hospital policy, none of the patients missed out a necessary surgical treatment and due to the existence of Reconstructive Hand surgery unit, patients were evaluated and had a follow up assessment by the consultant and the physiotherapist.

Patients during pre-pandemic period were assessed using tools such as Visual Analogue Scale (VAS), Quick-Dash questionnaire, grip strength measurements (Jamar Dynamometer) to evaluate the functional outcomes of the patients, range of motion, complications rate and received clinical assessment and Xrays to reassure the joint alignment and bone healing. Patients during pandemic period were assessed using the above tools in reduced visits due to quarantine restrictions and reduction of mobility.

Patients received a modified rehabilitation program by a specialised physiotherapist. They were trained in a home-based exercise programme during their 1st visit in Reconstructive hand surgery unit and then they followed a rehabilitation program in physiotherapy department which consisted of Continuous passive movement (CPM), ultrasound, assisted, active-assisted, active and later, strengthening exercises. The frequency of the physiotherapy sessions was changed according to the protocol which was decided by the medical services of the hospital to protect patients and staff from covid-19 infection. Due to visit restrictions of out-patients, physiotherapy sessions were delivered once a week during pandemic period, when necessary, otherwise patients performed the exercise program (in which they were trained of) without physiotherapy supervision but with guidance and communication though phone calls or tele-rehabilitation application especially in the 1 st semester of pandemic period (until June 2020) when people's mobility was dramatically reduced.

The assessment of patients with DRF during pandemic and especially at the end of 2020 was quite difficult because the quarantine in our city was even stricter at that time of the year, so the objective measurements were quite difficult to be reported. In most patients assessed until the end of 2020 the functional outcomes revealed through VAS and Quick dash measurements with a lot of restrictions.

\section{Data analysis}

The obtained data were statistically analysed using the Statistics Excel's program. Pearson's chi-square test was used to assess the relationship between the frequency distribution of responses in one variable with respect to the other variable and Fischer exact calculator test was used to compare groups with small sample. The value $\mathrm{p}<0.05$ was considered statistically significant.

\section{Results}

A total of 109 patients were included, 26 were female in prepandemic period (2018-2019), 25 were female in pandemic period (2020), 41 were male in pre-pandemic period and 17 were male in pandemic period with a $\mathrm{p}=.19$. The presence or absence of comorbidities didn't really affect patient admission, hospitalization, and selection of surgical treatment. (Table I, Graph.1)

To compare the quantitative variables, we used the Chisquared test with the $\mathrm{p}$ value adopted at the significance level $\mathrm{p}<$ 0.05. Statistical analysis was performed using the statistical package of Excel. Analyzing the data of the patients with distal 
radius fracture (DRF) surgically treated in Orthopedic department of the Venizeleio hospital between 2018 and 2019 year periods (referred as pre lock down period) and 2020 year (referred as lockdown period) we treated in total 32 cases 17 males (53\%) and 15 females $(46,8 \%), 35$ cases, 24 males $(68,57 \%)$ and 11 females $(31,42 \%)$ and 42 cases, 17 males $(40,47 \%)$ and 25 female $(59,52 \%)$ patients in each year respectively.(Table I) A chi-square test of independence showed that there was no statistically significant difference $(p=.19)$ between gender and total number of cases operated with distal radius fracture between the above years. The mean age of patients in year 2018 was $39,47 \pm 13,33$ (range, 19-63 male) and 57,93 $\pm 12,55$ (range29-62 female). The mean age of patients in year 2019 was $44,25 \pm 14,44$ (range 18-75 male) and $61,55 \pm 10,06$ (range 36-63 female). Finally, the mean age of patients in year 2020 was $45,88 \pm 10,70$ (range 28-62 male) and $52,25 \pm 17,81$ (range 20-74 female) as shown in Table II.

Comparing the extracted data referring to the causes of distal radius fracture between pre- lockdown and lock down periods we observed that the major causes were the vehicle accidents and the low-energy trauma. A Fisher exact test showed that $p=1$. With not statistically significance between the causes of trauma during the periods of time assessed. (Table III) It is quite remarkable that during pandemic period there was an increase in high-energy trauma with no incidence in pre-pandemic period, a fact that should be assessed thoroughly to extract safe conclusions.

The number of fractures observed to be slightly increased during pandemic period and especially the second semester of the lock-down period in our region. While 32 and 35 cases were treated in 2018, 2019, 42 cases were treated in 2020 with 9 $(21,42 \%)$ in the 1 st period of pandemic lockdown and $33(78,57 \%)$ in the second period of lockdown. (Table IV) There was statistical difference between the two pandemic periods in terms of number of subjects and gender correlation. $(\mathrm{p}=.34)$

In terms of predisposing factors of trauma in 2020 there was no reduction in vehicle accidents while low-energy trauma which is consisted mostly of domestic accidents increased slightly but there is an incidence of high-energy trauma. (Table $\mathbf{V}$ )

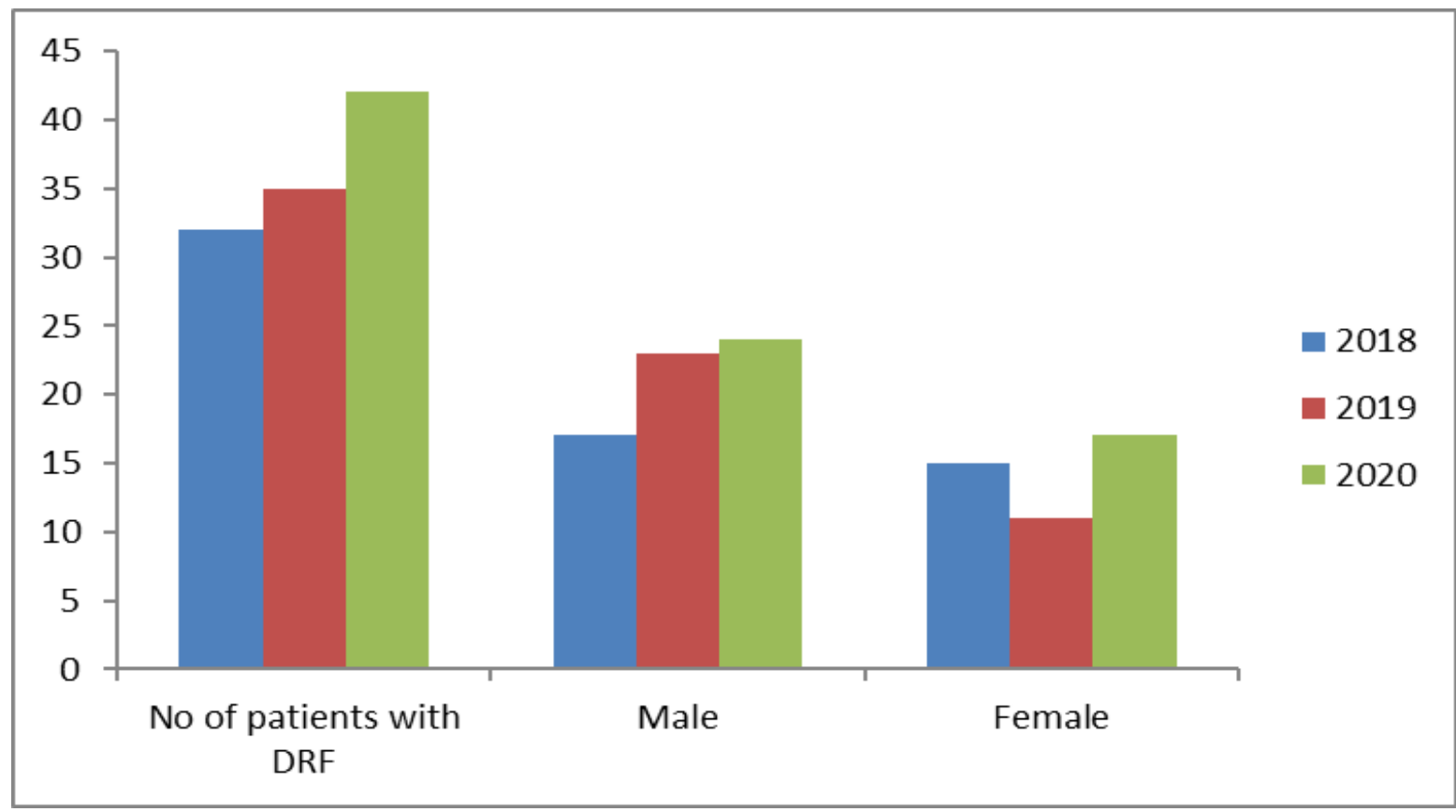

Graph.1 Number of subjects with DRF and gender distribution

Table I: Demographic data of patients with DRF in pre-pandemic and during pandemic periods.

\begin{tabular}{|l|l|l|l|}
\hline Year & No of patients with DRF & Male & Female \\
\hline $\mathbf{2 0 1 8}$ & 32 & $17(53 \%)$ & $15(46,8 \%)$ \\
\hline $\mathbf{2 0 1 9}$ & 35 & $24(68,57 \%)$ & $11(31,42 \%)$ \\
\hline $\mathbf{2 0 2 0}$ & 42 & $17(40,47 \%)$ & $25(59,52 \%)$ \\
\hline $\boldsymbol{P}$ value $=.19$ in total & & & \\
\hline
\end{tabular}

The result is not significant at $p<.05$.

Table II. Gender and age distribution during pre-lockdown $(2018,2019)$ and lock down $(2020)$ periods.

\begin{tabular}{|c|c|c|}
\hline & Female & Male \\
\hline & $\begin{array}{l}\text { Mean age } \pm \text { SD } \\
\text { (range, min.-max) }\end{array}$ & $\begin{array}{l}\text { Mean age } \pm \text { SD } \\
\text { (range, min.-max) }\end{array}$ \\
\hline 2018 & $\begin{array}{l}57,93 \pm 12,55 \\
\text { (range, } 29-62 \text { ) }\end{array}$ & $\begin{array}{l}39,47 \pm 13,33 \\
\text { (range, } 19-63 \text { ) }\end{array}$ \\
\hline 2019 & $\begin{array}{l}61,55 \pm 10,06 \\
\text { (range, 36-63) }\end{array}$ & $\begin{array}{l}44,25 \pm 14,44 \\
\text { (range, } 18-75 \text { ) }\end{array}$ \\
\hline 2020 & $\begin{array}{l}52,25 \pm 17,81 \\
\text { (range, } 20-74 \text { ) }\end{array}$ & $\begin{array}{l}45,88 \pm 10,70 \\
\text { (range, } 28-62 \text { ) }\end{array}$ \\
\hline P value $=.93$ & & \\
\hline
\end{tabular}

The result is not significant at $p<.05$. 
Table III. Distribution of causes of DRF pre- and during pandemic

\begin{tabular}{|c|c|c|c|c|}
\hline Causes of DRF & $\begin{array}{l}\text { Pre-lockdown } 2018 \\
\mathrm{~N}=32\end{array}$ & $\begin{array}{l}\text { Pre-lockdown } 2019 \\
\mathrm{~N}=35\end{array}$ & $\begin{array}{l}\text { During-lockdown } 2020 \\
\mathrm{~N}=42\end{array}$ & p-value \\
\hline Vehicle-accident & $15(46,87 \%)$ & $21(60 \%)$ & $23(54,76 \%)$ & $p=1$ \\
\hline High-energy trauma & 0 & 0 & $7(16,6 \%)$ & \\
\hline Low-energy trauma & $16(50 \%)$ & $10(28,57 \%)$ & $12(28,57 \%)$ & $p=1$ \\
\hline Polytrauma & $1(3,12 \%)$ & $4(11,42 \%)$ & 0 & \\
\hline
\end{tabular}

The result is not significant at $p<.05$.

Table IV. Gender distribution and cause of trauma during $1^{\text {st }}$ and $2^{\text {nd }}$ pandemic periods

\begin{tabular}{|l|l|l|l|l|l|}
\hline & $\begin{array}{l}\text { Number of subjects } \\
\text { with DRF }\end{array}$ & $\begin{array}{l}\text { Number of } \\
\text { Males }\end{array}$ & $\begin{array}{l}\text { Number of } \\
\text { Females }\end{array}$ & $\begin{array}{l}\text { Number of } \\
\text { vehicle accidents }\end{array}$ & $\begin{array}{l}\text { Number of low } \\
\text { energy trauma }\end{array}$ \\
\hline During-lockdown $2020 \mathbf{1}^{\text {st }}$ period & $\mathrm{N}=9$ & $\mathrm{~N}=5(55,5 \%)$ & $\mathrm{N}=4(44,4 \%)$ & $\mathrm{N}=8(88,8 \%)$ & $\mathrm{N}=1(11,1 \%)$ \\
\hline During-lockdown $20202^{\text {nd }}$ period & $\mathrm{N}=33$ & $\mathrm{~N}=12(36,36 \%)$ & $\mathrm{N}=21(63,6 \%)$ & $\mathrm{N}=15(45,45 \%)$ & $\mathrm{N}=11(33,33 \%)$ \\
\hline
\end{tabular}

Table V. Gender and distribution of causes of DRF

\begin{tabular}{|c|c|c|c|c|}
\hline $\begin{array}{l}\text { CAUSES of DRF } \\
\mathrm{N}=42\end{array}$ & $\begin{array}{l}\text { During-lockdown } 2020 \\
1^{\text {st }} \text { period } \\
\mathrm{N}=9 \\
\text { Male(5) }\end{array}$ & $\begin{array}{l}\text { During-lockdown } 2020 \\
1^{\text {st }} \text { period } \\
\mathrm{N}=9 \\
\text { Female(4) }\end{array}$ & $\begin{array}{l}\text { During-lockdown } 2020 \\
2^{\text {nd }} \text { period } \\
\mathrm{N}=33 \\
\text { Male(12) }\end{array}$ & $\begin{array}{l}\text { During-lockdown } 2020 \\
2^{\text {nd }} \text { period } \\
\mathrm{N}=33 \\
\text { Female }(21)\end{array}$ \\
\hline Vehicle-accident & 5 & 3 & 12 & 3 \\
\hline High-energy trauma & 0 & 0 & 0 & 7 \\
\hline Low-energy trauma & 0 & 1 & 0 & 11 \\
\hline Polytrauma & 0 & 0 & 0 & 0 \\
\hline P value $=.34$ & & & & \\
\hline
\end{tabular}

The result is not significant at $p<.05$.

\section{Discussion}

Distal radius fractures constitute a common orthopaedic trauma met in emergency department and a remarkable social problem. Most patients with DRF trauma seeking medical help in emergency department need surgical treatment if meeting certain criteria as displaced distal radius fracture with an intra-articular step of more than $2 \mathrm{~mm}$, radial shortening more than $2 \mathrm{~mm}$, dorsal tilt more than15 degree, incongruence in distal radio-ulnar joint in preoperative $\mathrm{x}$-rays or $\mathrm{ct} / \mathrm{scan}$ and bilateral $\mathrm{DRF}^{[2]}$.

In January 2020 the Corona-virus disease (COVID-19) had already started to spread rapidly around the world and was declared as a global pandemic by the World Health Organization on 11 March 2020. During the pandemic period there was a strict time of lockdown in the first semester and a lesser strict period of lockdown in the last 3 months of the year. Distal radius fracture surgery performed during lockdown with no obstacle due to acute trauma, although there was a limitation in rehabilitation sessions due to quarantine restrictions and hospital policy. The first case in Greece was reported at the end of February, so after the declaration of pandemic, the Greek government decided to impose a quarantine with quite strict conditions for the whole population of the country.

The COVID-19 pandemic has had a considerable impact on the lives of both adults and children around the world ${ }^{[10]}$. This could not be different for Greece and especially in island country where there was a definite restriction in transportation and communication with the rest of the country. Schools have been closed, causing children to stay at home, and some adults worked from home. Moreover, during the first COVID-19 pandemic period until the end of May, people's ability to move outdoors was severely limited, due to government-imposed restrictions, so it is really expected to have a decrease in trauma cases ${ }^{[15,18]}$. It is referred in literature that reduced incidence of extremity fractures was associated with the decreased activity and mobility level due to pandemic restrictions ${ }^{[10,11]}$. But is this always the case?

The practice of orthopedics and physical therapy were also affected by the pandemic as reported by many authors according to various
Orthopedic association guidelines and government's restrictions $[5,19,21]$. It is knowledgeable that the health system of each country had to deal with patients with COVID-19 with quite emerged circumstances especially in general hospitals in rural and in islands. A few studies have been done to assess the epidemiology of extremities fracture during pandemic and the impact in treatment and rehabilitation of these traumas ${ }^{[23]}$. In most cases, studies describe descriptively the type and incidence of various orthopedic traumas admitted in emergency department ${ }^{[12,13]}$. It is reported a decreased incidence of injuries due to sports and other outdoor activities and an increased incidence of high-energy injuries due to falls from trampolines and bicycles. Lv et al also observed a $42 \%$ decrease in the number of patients with fractures seen at one orthopedic department in China during the COVID-19 epidemic $^{[14]}$.

Additionally, there have been no studies evaluating during pandemic period the important issue of epidemiology and treatment of DRFs in adults, although there are some studies referring to children ${ }^{[15]}$. Nabian et al. presented epidemiological data of pediatric injuries during the COVID-19 pandemic from a tertiary trauma center in Iran ${ }^{[11]}$. It is quite interesting that an increased percentage of DRFs in children during the COVID-19 pandemic was observed. According to Bram et al. who also assessed the effects of the COVID-19 pandemic on the epidemiology of injuries in pediatric patients, the total number of fractures decreased by $61 \%$, and there were no changes in the male-to-female ratio while the mean age of patients decreased ${ }^{[7]}$. But many authors describe the options, adaptations, and possibilities they had to manage patients with DRF visiting Emergency Department in various countries based on governments and hospital policies ${ }^{[15,17,18,19]}$. Baawa-Ameyaw reported that $54 \%$ of 92 patients with DRF were managed nonoperatively due to restrictions in clinical practice, although they had indications for surgical treatment ${ }^{[8]}$. Jerome et al reported a $28.6 \%$ decrease in number of patients received operative treatment due to hand and wrist trauma in one of Italian hospitals during the COVID-19 pandemic ${ }^{[9]}$. Lockey reported a decrease in both elective and emergency admissions to orthopedic wards, with no differences in 
terms of gender and age in patients in pre-pandemic and during COVID-19 pandemic periods ${ }^{[20]}$.

Although in most studies reported in literature there is a decrease in the incidence of radius fractures this is not the case in our hospital based on island of Crete. The most significant finding of our study was an increase in the second half of pandemic period in the number of patients presenting in emergency department with DRF trauma comparing to the equivalent period in 2019. This is due to limitation of quarantine restrictions which was done during summer period and return to normal activities. The psychological impact of quarantine and the change of lifestyle due to summer could promote an increase of mobility with lesser precautions in both local and visitor's population. However, it is quite important to notify that there was no statistically significant difference in the incidence of DRF due to vehicle accidents during pandemic period, but there was a remarkable increase in low-energy trauma which refers mostly in domestic accidents. A reduction in daily activities because of prolonged quarantine conditions could lead in reduction of body mass and in increase in fatty tissue and BMI. The above factors are concerned to be predisposing factors of osteoporosis as well as deficiency of vitamin-D which is quite common in Crete. The above data could explain the increase of DRF fracture due to low-energy trauma after the strict quarantine period ${ }^{[11,12,13]}$.

During the COVID period, a reduced number of health services is often provided in various countries. However, subjects seemed to remain exposed to hand trauma and especially to lowenergy traumas (falls) ${ }^{[13,22]}$. The time to surgery decreased slightly in 2020, probably because there was no elective surgical activity due to hospital policy so quick resolution of urgent patients was achieved. To avoid prolonged hospitalizations and reduce the risk of acquiring SARS-CoV-2 infection, patients were discharged nearly the day after, and a follow-up screening been done through the Reconstructive Hand Surgery unit. It was quite important to evaluate patients regularly and reassure that they follow their personalized rehabilitation program, by the physiotherapist of the unit. Although in some cases the objective measurements were difficult to assess, it was quite a success that patients were communicating with us in any way.

There was not statistically difference also in terms of gender or age concerning the number of subjects with DRF visiting the Hand Reconstructive unit although it must be highlighted that women had a more increased incidence probably due to reduction of mobility or Vitamin D deficiency ${ }^{[14]}$.

The limitations of our study are primarily that is conducted in a single center, based on a general hospital in an island and therefore the number of patients treated was relatively low and that the epidemiology of DRF during the COVID-19 pandemic may be influenced by other factors, such as medical and bioethical framework as well as quarantine restrictions.

\section{Conclusion}

Our study showed that there is an impact of the COVID-19 pandemic on the epidemiology and the methodology of rehabilitation of DRFs in adults. We found slightly increased number of adult patients with DRFs who were referred to trauma center of the hospital during the COVID-19 pandemic. Adaptation in management of distal radius fracture during lockdown did not affect patient's surgical treatment but only the rehabilitation sessions, which were reorganised according to hospital policy guidelines and quarantine restrictions. It is crucial for patients with DRF to have holistic approach to achieve a complete rehabilitation, by personalising the treatment plan and using alternative communication tools such as tele rehabilitation and phone call as motivational elements for good functional outcomes.

\section{Ethical Approval}

The Institutional Ethical Committee approved this study.

\section{Competing Interests}

Authors have declared that no competing interests exist.

\section{References}

[1] Huetteman HE, Zhong L, Chung KC. (2018) Cost of surgical treatment for distal radius fractures and the implications of episode-based bundled payments. J Hand Surg.; 43(8):720-30, doi:10.1016/j.jhsa.2018.05.007.

[2] Kastanis G., Pantouvaki A.,Kapsetakis p. Spyrantis E.. Stavrakakis I.Volar Locking Plate for Distal Radius Fractures: Functional Outcomes and Complication Rates with a Minimum of One Year Follow-Up. International Journal of innovative research in medical sciences.2021;6(5):358-365, doi.org/10.23958/ijirms/vol06-i05/1131

[3] Coronavirus disease (COVID-19) 2020.Information for Healthcare professionals and settings.https://eody.gov.gr/

[4] BOA Standards for Trauma and Orthopaedics (BOASTs). (2021)The management of distal radius fractures. www.boa.ac.uk

[5] BOA Standards for Trauma and Orthopaedics (BOASTs). (2020) Management of patients with urgent orthopaedic confitions and trauma during the coronavirus pandemic 2020 www.boa.ac.uk

[6] Upadhyaya GK, Iyengar K, Jain VK, Vaishya R. Challenges and strategies in management of osteoporosis and fragility fracture care during COVID-19 pandemic $\mathrm{J}$ Orthop. 2020; 2(21):287-290, doi:10.1016/j.jor.2020.06.001

[7] Bram JT, Johnson MA, Magee LC, Mehta NN, Fazal FZ, Baldwin KD, Riley J, Shah AS. Where Have All the Fractures Gone? The Epidemiology of Pediatric Fractures During the COVID-19 Pandemic. J Pediatr Orthop.2020;40(8):373-379.

doi:10. 1097/BPO.0000000000001600.

[8] Baawa-Ameyaw J, Kabariti R, Chandra A, Rhee J. The theoretical impact on corrective upper limb elective services following analysis of distal radius fractures managed non-operatively during COVID-19 pandemic. Bone Jt Open. 2020;1(10):612-616, doi: 10.1302/26331462.110.BJO-2020-0126.R1.

[9] Jerome JTJ, Mercier F, Mudgal CS, Arenas-Prat J, Vinagre G, Goorens CK,Rivera-Chavarría IJ, Sechachalam S, Mofikoya B, Thoma A, Medina C;IlavarasuTamilmani, Rivera-Chavarría IJ, Henry M, Afshar A, Dailiana ZH,Prasetyono TOH, Artiaco S, Madhusudhan TR, Ukaj S, Reigstad O, Hamada Y, Bedi R,Poggetti A, Al-Qattan MM, Siala M, Viswanathan A, Romero-Reveron R, Hong JP,Khalid KA, Bhaskaran S, Venkatadass $\mathrm{K}$, Leechavengvongs $\mathrm{S}$, Goorens $\mathrm{CK}$, Nazim S,Georgescu AV, TrempM, Nakarmi KK, Ellabban MA, Chan P, Aristov A, Patel S,MorenoSerrano CL, Rai S, Kanna RM, Malshikare VA, Tanabe K, Thomas S, Gokkus K, Baek SH, Brandt J, Rith Y, 
Olazabal A, Saaiq M, Patil V, Jithendran N, Parekh H, Minamikawa Y, Atagawi AA, Hadi JA, Berezowsky CA, Moya-Angeler J, Altamirano-Cruz MA, Galvis R LA, Antezana A, Paczesny L, Fernandes CH, Asadullah M, Yuan-Shun L, Makelov B, Dodakundi C, Regmi R, Pereira GU, Zhang S, Sayoojianadhan B, Callupe I, Rakha MI, Papes D, Ganesan RP, Mohan M, Jeyaraman A, Prabhakar P, Rajniashokan A, Geethan I, Chandrasekar S, Löw S, Thangavelu K, Giudici LD, Palanisamy Y, Vaidyanathan S, Boretto J, Ramirez MA, Goundar TS, Kuppusamy T, Kanniyan K, Srivastava A, Chiu YC, Bhat AK, Gopinath NR, Vasudevan VP, Abraham V.(2020) Perspectives and Consensu among International Orthopaedic Surgeons during initial and Mid- lockdown Phases of Coronavirus Disease. J Hand Microsurg.2020:12(3):135-162,doi: 10.1055/s-0040-171 3964.

[10] Nabian MH, Vosoughi F, Najafi F, Khabiri SS, Nafisi M, Veisi J, Rastgou V,Ghamari S, Aakhashi A, Bahrami N, Naderi M, Maleki S, Yekaninejad MS. Epidemiological pattern of pediatric trauma in COVID-19 outbreak: Data from atertiary trauma centerin Iran.In jury.2020:51(12):2811-2815.doi:

10.1016/j.injury.2020.09.015

[11] Mahapatra S, Tripathi SS, Kumar V, Ambasta S, Agarwal A, Yadav RRS, Krishna D. Evaluation of Patterns of Trauma Reporting to the Emergency Department During the First COVID-19 Lockdown in India. Cureus. 2021 ;13(4): e14609, doi:10.7759/ cureus.14609.

[12] Sephton BM, Mahapatra P, Shenouda M, Ferran N, Deierl K, Sinnett T,Somashekar N,Sarraf KM, Nathwani D, Bhattacharya R. The effect of COVID-19 on a Major Trauma Network. An analysis of mechanism of injury pattern, referral load and perative case mix. Injury. 2021;52(3):395-401. doi: 10.1016/j.injury.2021.02.035.

[13] Lv H, Zhang Q, Yin $Y$ et al.Epidemiologic characteristics of traumatic fracturesduring the outbreak of coronavirus disease 2019 (COVID-19) in China: A retrospective \& comparative multi-center study. Injury. 2020;51(8):1698-1704.
[14] Moro T, Paoli A.When COVID-19 affects muscle: effects of quarantine in older adults Eur J Transl Myol. 2020;30(2):9069.

[15] Gallè F, Sabella EA, Ferracuti $S$ et al. Sedentary Behaviors and Physical Activity of Italian Undergraduate Students during Lockdown at the Time of CoViD-19 Pandemic. Int J Environ Res Public Health.2020;17(17):6171.

[16] Yengar K, Vaish A, Vaishya R. Revisiting conservative orthopaedic management of fractures during COVID-19 pandemic. J Clin Orthop Trauma.2020;11(4):718-720

[17] R, Kopel L, Lejeune Q, Masmoudi R, Masmejean EH Impact of the corona virus Disease 2019 lockdown on hand and upper limb emergencies: experience of a referred university trauma hand centre in Paris, France. Int Orthop.2020;44(8):1497 1501. doi: 10.1007/s00264020-04654-2

[18] Ribau A, Vale J, Xara -Leite F, Pinto RR..Impact of COVID-19 pandemic and national lockdown in an orthopaedic and traumatology department a comparison with the homologous period of 2019 Porto Biomed J. 2021;6(1): e109.doi:10.1097/j.pbj. 0000000000000109

[19] Vijay Kumar Jain, Hitesh Lal, Mohit Kumar Patralekh, Raju Vaishya. Fracture management during COVID-19 pandemic: A systematic Review. J Clin Orthop Trauma.2020;11(Suppl 4):s431-s441, doi:10,1016/j.jcot.2020.06.035.

[20] Lockey SD, Nelson PC, Kessler MJ, Kessler MW. Approaching "Elective" Surgery in the Era of COVID19. J Hand Surg Am.2021;46(1):60-64. doi: 10.1016 /j. jhsa. 2020.09.006.

[21] Harvey J, Varghese BJ, Hahn DM. Displaced distal radius fracture: reduction, follow-up, and clinical outcomes: learning from a pragmatic approach during the 2020 COVID-19 lockdown transition. Bone Jt Open. 2021;2(5):338-343. doi:10.1302/ 2633-1462.25.BJO2021-0015

[22] Olech J, Ciszewski M, Morasiewicz P.Epidemiology of distal radius fractures in children and adults during the COVID-19 pandemic - a two-center study. BMC Musculoskelet Disord. 2021;22(1):306. doi: 10.1186/s12891-021-04128-5. 